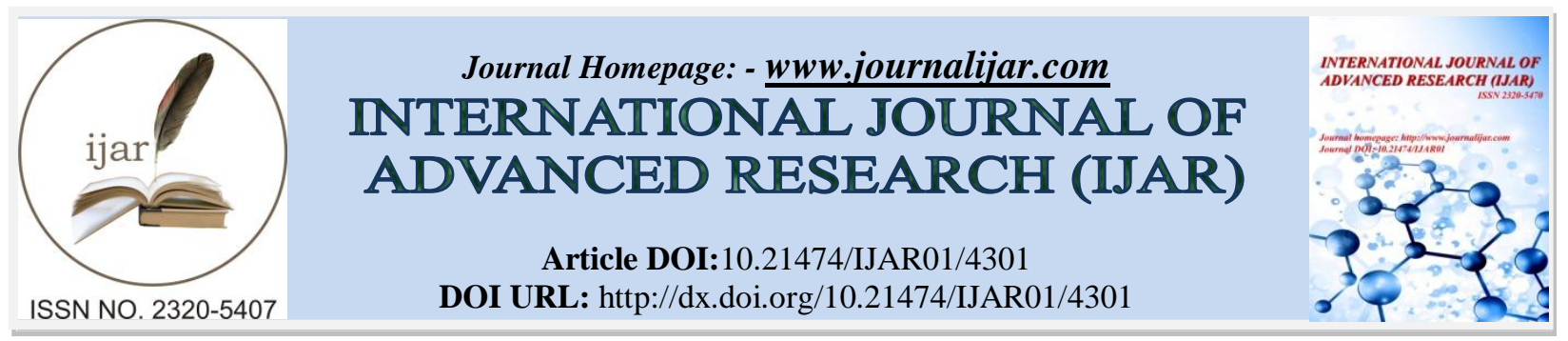

RESEARCH ARTICLE

\title{
DOPPLER ULTRASONOGRAPHIC ANALYSIS OF THE VERTEBRAL ARTERY BLOOD FLOW DURING CERVICAL MANUAL TRACTION.
}

\author{
Shhalini Grover. \\ Associate Professor, Department of Physiotherapy,Faculty of Applied Science Manav Rachna International \\ University.
}

\section{Manuscript Info}

......................

Manuscript History

Received: 18 March 2017

Final Accepted: 22 April 2017

Published: May 2017

Key words:-

Cervical manual traction, Vertebrobasillary insufficiency(VBI), Peak

systolic velocity(PSv), end diastolic velocity(EDv)

\section{Abstract}

The vertebral artery in the neck region has a unique relationship with the cervical spine as well as with the muscle, ligaments and disc of the cervical region. The vertebral artery supplies $20 \%$ of the blood to the brain which has the major role in brain functioning. Various movements of the cervical spine affect the flow of blood in the vertebrobasilar artery. During normal rotation movement of the cervical spine, the vertebral artery can easily get stretched without being damaged because of its natural tortusity. It has been proposed that the movement of the head specially rotation and extension may interfere the blood flow and give rise to the symptoms of vertebrobasilary insufficiency. The present study was conducted to analyze the measurement of blood flow of vertebral artery during cervical c1-c2 manual therapy traction ultrasonographically. 42 subjects were analyzed with Doppler ultrasonography at the level of c1-c2 in neutral cervical spine without any rotation and also during cervical manual traction intervention. During cervical manual traction (mulligan c1-c2) the blood flow velocity of vertebral artery in terms of peak systolic velocity (PSv) and End diastolic velocity (EDv) increased significantly. Thus the study concluded that there was an increase of blood flow velocity during cervical manual traction.

Copy Right, IJAR, 2017,. All rights reserved.

\section{Introduction:-}

The vertebral artery is unique among the neck vessels by virtue of its position with the cervical spine and relationship to the adjacent muscle, ligaments \& disc etc. It supplies majorly to musculoskeletal structures of the cervical spine and to the cervical spinal cord. (Moore \& Dalley 1999). The vertebral artery has four division depending upon its location during its course ; the first part located in the root of the neck to the sixth cervical vertebra ,this part branched from the subclavian artery, second part transverses from sixth cervical vertebra to first cervical vertebra, the artery runs through the foramina transversaria of all six cervical vertebrae ; third part which is also known as suboccipital part of artery located from the first cervical vertebra(atlas) to the dura mater at the foramen magnum and the fourth part which is intracranial lies within the cranium to the pontomedullary border (ElBary and Dujovny 1995; Anderson \& Bannister 1989). Between atlas and axis, the vertebral artery follows tortuous course and at suboccipital region, the artery takes a loop of approximately 90 degree passes postero-medially to the lateral mass of the atlas before entering the spinal canal. The connective tissues make the artery almost fixed in this region. (Mann $2001 \&$ Mitchell 2005) . 
The vertebral artery plays a major role in providing the posterior circulation to the brain and maintaining function of brainstem. The blood flow of the vertebral artery decreases with contralateral or ipsilateral rotation of the cervical spine (Arnold 2004) as with cervical rotation, the contralateral vertebral artery can be stretched across the rim of foramen transversarium (Haynes and Milne, 2001) and the ipsilateral side can be compressed against the rim of the lateral mass (Bolton, Stick, and Lord, 1989). Whether ipsilateral or contralateral side of cervical movements or premanipulative hold which involves sustained extension with cervical rotation, there is reduction of flow of blood in the vertebral artery(Mitchell 2003) because all these positions stresses the artery mechanically and cause decrease in blood flow velocity of vertebral artery.

Various techniques are being used for measuring the blood flow status of vertebral artery. Among all are Magnetic resonance angiography (MRA), invasive electromagnetic flow metery (EMF), color Doppler Ultrasound (CDU) are used. For measuring the blood flow in the extra cranial part of vertebral artery, colour Doppler ultrasonography is the first choice (Ozdemir, et al 2005). Doppler ultrasound is a non-invasive painless and easily administered diagnostic test use to measure the real time blood flow at various point of the artery. (Johnson et al 2007).

\section{Material and Methods:-}

There were 42 healthy young adults age $24.66 \pm 2.008$ participated in this study according to the inclusion criteria and excluded if there were history of serious cervical spine trauma, fracture, instability or any congenital abnormality of cervical spine, dizziness/vertigo of any reason. The participants should not have any pain, tightness ,stiffness of neck muscles which could restrict the neck movement. Doppler ultrasound measurements were taken for the blood flow velocity. Peak systolic velocity (PSv) and End diastolic velocity(EDv) were considered while measuring blood flow velocity. These measurement were taken with Doppler US machine (Philips HDI 5000; Philips Medical Systems) having a $7.5 \mathrm{MHz}$ linear array transducer. The participants were in a supine lying position with neutral cervical position without pillow. The probe was angled approximately 6o degree on the lateral side of the neck anterior to the sternocleidomastoid muscle and maneuvered to locate the underlying vertebral artery, so that an audible and the sharpest visual representations of blood flow in the artery of right and left side could be obtained. The same ultrasonic measurement were taken during cervical manual traction at c1-c2 (Mulligan mobilization) Mulligan (1993) .

\section{Result and Discussion:-}

Descriptive statistics included mean, standard deviation, standard error and 95\% confidence intervals between baseline and during manual traction. The variables like peak systolic velocity(PSv) and end diastolic velocity( EDv) were considered. These variables were tested using kolmogorov-Smirnov,s test. As the data were following the normal distribution, the parametric test was done for analysis. These pair-wise differences were analyzed for statistical significance with using paired t-tests. All statistical tests were completed using SPSS 21 version. The significance level was set at 0.000 .

Table1: -shows Mean,SD and 95\% CI for mean of age of all participants of the study

\begin{tabular}{|l|l|l|l|l|l|l|}
\hline Variables & Mean & S.D & Minimum & Maximum & \multicolumn{2}{|l|}{ 95\% CI for mean } \\
\cline { 6 - 7 } & & & & & Lower Bound & Upper Bound \\
\hline Age & 24.66 & 2.008 & 21.00 & 29.00 & 24.0409 & 25.2924 \\
\hline
\end{tabular}

Table 2:- Means and SD of blood flow velocity in terms of peak systolic velocity (PSV), end diastolic velocity(EDV) of left and right vertebral artery .

\begin{tabular}{|l|l|c|l|c|c|c|}
\hline & SIDE & Mean Difference & SEM & $\begin{array}{l}95 \% \text { CI } \\
\text { (Lower,Upper) }\end{array}$ & t Value & P Value \\
\hline $\begin{array}{l}\text { Pre-Post } \\
\text { PSV(Rt) }\end{array}$ & RT & -4.98333 & 1.16002 & $-7.32605,-2.64062$ & -4.296 & .000 \\
\hline $\begin{array}{l}\text { Pre-Post } \\
\text { PSV(Lt) }\end{array}$ & LT & -4.25000 & 0.77610 & $-5.81736,-2.68264$ & -5.476 & .000 \\
\hline $\begin{array}{l}\text { Pre-Post } \\
\text { EDV(Rt) }\end{array}$ & RT & -5.64143 & .93788 & $-7.53552,-3.74733$ & -6.015 & .000 \\
\hline $\begin{array}{l}\text { Pre-Post } \\
\text { EDV(Lt) }\end{array}$ & LT & -3.48571 & .55375 & $-4.60403,-2.36739$ & -6.295 & .000 \\
\hline
\end{tabular}


Table 3:-Difference of mean of blood flow velocity Peak systolic velocity(PSV), end diastolic velocity(EDV) of left and right vertebral artery in neutral position and during manual traction position with $\mathrm{P}$ value.

\begin{tabular}{|l|l|l|l|l|l|l|l|}
\hline $\begin{array}{l}\text { Outcome } \\
\text { Parameters }\end{array}$ & $\mathrm{N}$ & Mean & SD & Minimum & Maximum & 95\% CI for mean & $\begin{array}{l}\text { 95\% CI for } \\
\text { mean }\end{array}$ \\
\hline Pre-PSV (Rt) & 42 & 58.879 & 9.86 & 25.50 & 72.60 & 55.807 & 61.950 \\
\hline Post-PSV (Rt) & 42 & 63.862 & 11.59 & 29.90 & 85.60 & 60.249 & 67.474 \\
\hline Pre-PSV (Lt) & 42 & 63.06 & 10.24 & 48.70 & 92.70 & 59.869 & 66.253 \\
\hline POST-PSV (Lt) & 42 & 67.31 & 11.63 & 48.70 & 92.90 & 63.687 & 70.936 \\
\hline Pre-EDV (Rt) & 42 & 23.95 & 5.70 & 9.80 & 37.20 & 22.173 & 25.727 \\
\hline POST-EDV (Rt) & 42 & 29.59 & 8.58 & 8.64 & 47.10 & 26.918 & 32.264 \\
\hline Pre-EDV (Lt) & 42 & 25.81 & 4.55 & 15.90 & 36.90 & 24.395 & 27.232 \\
\hline POST-EDV (Lt) & 42 & 29.30 & 6.27 & 15.80 & 42.90 & 27.346 & 31.253 \\
\hline
\end{tabular}

\section{Discussion:-}

This present study was focused on to see the changes in blood flow velocity of vertebral artery during cervical manual traction as compared to neutral position using Doppler ultrasonography. The results of this study suggested that there were significantly change in the vertebral artery blood flow velocity during cervical manual traction. Previous studies observed decrease in blood flow of vertebral artery during contralateral neck rotation .( Mitchell ,2008). An ultrasound study on individuals showed marked reduction of blood flow in vertebral artery with neck rotation, but still there was no signs and symptoms believed there was no compromise in the blood supply to brain (Rivett et al 1999). In the anxious state or in any mental task done by an individual, a change of $<10 \%$ in blood volume flow in the vertebral artery was investigated (Kreiger et al 2012).

The results of current study analyzed that during cervical manual traction at c1-c2 level mentioned by mulligan, there were statistically significant changes in blood flow velocity in terms of peak systolic velocity and end diastolic velocity. Various movements such as sustained end range rotation of cervical spine stresses the vertebral artery thus decreases the blood flow in the vertebral artery (Mitchell J 2005). This current study focused on measuring the blood flow velocity during manual traction without doing any cervical rotation thus stretching and compression of the artery was avoided.

\section{Conclusion:-}

This study concluded that cervical manual traction technique had a significant effect on haemodynamic status of vertebral artery with no mechanical stress on the artery. As such, this study is of great value in increasing the knowledge of the possible technique used for the treatment related to the blood flow changes of vertebral artery in cervical spine.

\section{Reference:-}

1. Moore, K.L. and Arthur, F., 1999. Dalley. Clinically Oriented Anatomy.

2. El-Bary, T.H.A., Dujovny, M. and Ausman, J.I., 1995. Microsurgical anatomy of the atlantal part of the vertebral artery. Surgical neurology, 44(4), pp.392-401.

3. Mitchell J. The vertebral artery: a review of anatomical, histopathological and functional factors influencing blood flow to the hindbrain. Physiotherapy theory and practice. 2005 Jan 1;21(1):23-36

4. Arnold, C., Bourassa, R., Langer, T. and Stoneham, G., 2004. Doppler studies evaluating the effect of a physical therapy screening protocol on vertebral artery blood flow. Manual therapy, 9(1), pp.13-21.

5. Haynes, M.J. and Milne, N., 2001. Color duplex sonographic findings in human vertebral arteries during cervical rotation. Journal of Clinical Ultrasound, 29(1), pp.14-24.

6. Bolton, P.S., Stick, P.E. and Lord, R.S., 1989. Failure of clinical tests to predict cerebral ischemia before neck manipulation. Journal of Manipulative and Physiological Therapeutics, 12(4), p.304.

7. Mitchell, J.A., 2003. Changes in vertebral artery blood flow following normal rotation of the cervical spine. Journal of Manipulative and Physiological Therapeutics, 26(6), pp.347-351.

8. Johnson, E.G., Houle, S., Perez, A., Lucas, S.S. and Papa, D., 2007. Relationship between the duplex Doppler ultrasound and a questionnaire screening for positional tolerance of the cervical spine in subjects with suspected vascular pathology: a case series pilot study. Journal of Manual \& Manipulative Therapy, 15(4), pp.225-230. 
9. Krieger SAN, Streicher MN, Trampel R, Turner RD. ,2012. Cerebral blood volume changes during brain activation. J. Cereb Blood Flow Metab. 32:1618-1631

10. Mitchell J, Kramschuster K., 2008 .Real-time ultrasound measurements of changes in suboccipital vertebral artery diameter and blood flow velocity associated with cervical spine rotation. Physiotherapy Research International. Dec 1;13(4):241-54.

11. Mitchell J. , 2005.The vertebral artery: a review of anatomical, histopathological and functional factors influencing blood flow to the hindbrain. Physiotherapy theory and practice. Jan 1;21(1):23-36.

12. Rivett DA. ,2004. The vertebral artery and vertebrobasilar insufficiency. Bouling JD, Jull GA. Greive's Modern Manual Therapy, The Vertebral Column. Third ed. London: Elsevier Churchill Livingstone. 257-73. 